\title{
Assessments of residential and global positioning system activity space for food environments, body mass index and blood pressure among low-income housing residents in New York City
}

\author{
Kosuke Tamura, ${ }^{1}$ Brian Elbel, ${ }^{2,3}$ Jessica K. Athens, ${ }^{2}$ Pasquale E. Rummo, ${ }^{2}$ Basile Chaix, \\ Seann D. Regan, ${ }^{2}$ Yazan A. Al-Ajlouni, ${ }^{2}$ Dustin T. Duncan ${ }^{2}$ \\ ${ }^{1}$ Cardiovascular Branch, Division of Intramural Research, National Heart, Lung, and Blood Institute, \\ National Institutes of Health, Bethesda, Maryland, USA; ${ }^{2}$ Department of Population Health, New York \\ University School of Medicine, New York, NY, USA; ${ }^{3}$ Wagner Graduate School of Public Service, New York \\ University, New York, NY, USA; ${ }^{4}$ Sorbonne Universités, UPMC Univ Paris 06, UMR S 1136, Pierre Louis \\ Institute of Epidemiology and Public Health, Paris, France; ${ }^{5}$ Inserm, UMR S 1136, Pierre Louis Institute of \\ Epidemiology and Public Health, Paris, France
}

\begin{abstract}
Research has examined how the food environment affects the risk of cardiovascular disease (CVD). Many studies have focused
\end{abstract}

Correspondence: Kosuke Tamura, Cardiovascular Branch, Division of Intramural Research, National Heart, Lung, and Blood Institute, National Institutes of Health, 10 Center Drive, Building 10-CRC, Bethesda, MD 20892, Maryland, USA.

Tel.: +81.301.827.8660 - Fax: +81.301.402.0888.

E-mail: kosuke.tamura@nih.gov

Key words: Neighbourhood food environment; Low-income housing residents; Geographic information systems; Global positioning systems; Health disparities.

Acknowledgements: the authors thank the research assistants for this project: Maliyhah Al-Bayan; Shilpa Dutta; William Goedel; Brittany Gozlan; Kenneth Pass; James Williams; and Abebayehu Yilma. We thank Jeff Blossom for geocoding the participants' addresses. Finally, we thank the participants for engaging in this research.

Contributions: DD data collection; KT data analysis and manuscript writing; BE, JA, PR, BC, SR, YA, DD manuscript reviewing.

Conflict of interest: the authors declare no potential conflict of interest.

Funding: the NYC Low-Income Housing, Neighborhoods and Health Study was supported by the NYU-HHC Clinical and Translational Science Institute (CTSI) Pilot Project Awards Program (Dr. Dustin Duncan, Principal Investigator)

Received for publication: 24 May 2018.

Revision received: 23 August 2018.

Accepted for publication: 1 October 2018.

CCopyright K. Tamura et al., 2018

Licensee PAGEPress, Italy

Geospatial Health 2018; 13:712

doi:10.4081/gh.2018.712

This article is distributed under the terms of the Creative Commons Attribution Noncommercial License (CC BY-NC 4.0) which permits any noncommercial use, distribution, and reproduction in any medium, provided the original author(s) and source are credited. on residential neighbourhoods, neglecting the activity spaces of individuals. The objective of this study was to investigate whether food environments in both residential and global positioning system (GPS)-defined activity space buffers are associated with body mass index (BMI) and blood pressure (BP) among low-income adults. Data came from the New York City Low Income Housing, Neighborhoods and Health Study, including BMI and BP data $(n=102$, age $=39.3 \pm 14.1$ years $)$, and one week of GPS data. Five food environment variables around residential and GPS buffers included: fast-food restaurants, wait-service restaurants, corner stores, grocery stores, and supermarkets. We examined associations between food environments and BMI, systolic and diastolic $\mathrm{BP}$, controlling for individual- and neighbourhood-level sociodemographics and population density. Within residential buffers, a higher grocery store density was associated with lower BMI $(\beta=-$ $\left.0.20 \mathrm{~kg} / \mathrm{m}^{2}, \mathrm{P}<0.05\right)$, and systolic and diastolic BP $(\beta=-1.16 \mathrm{~mm}$ $\mathrm{Hg}$; and $\beta=-1.02 \mathrm{~mm} \mathrm{Hg}, \mathrm{P}<0.01$, respectively). In contrast, a higher supermarket density was associated with higher systolic and diastolic $\mathrm{BP}(\beta=1.74 \mathrm{~mm} \mathrm{Hg}, \mathrm{P}<0.05$; and $\beta=1.68, \mathrm{P}<0.01$, respectively) within residential buffers. In GPS neighbourhoods, no associations were documented. Examining how food environments are associated with CVD risk and how differences in relationships vary by buffer types have the potential to shed light on determinants of CVD risk. Further research is needed to investigate these relationships, including refined measures of spatial accessibility/exposure, considering individual's mobility.

\section{Introduction}

Obesity and hypertension are thought to be significant public health issues in the general U.S. population (Narkiewicz, 2006; Kurukulasuriya et al., 2011). Nearly 75 million U.S. adults (about 1 in 3; 32\%) have high blood pressure (BP) (i.e. systolic BP $\geq 140$ millimetre of mercury [mmHg]; diastolic $\mathrm{BP} \geq 90 \mathrm{mmHg}$ ) (Merai et al., 2016), contributing to the deaths of over 400,000 individuals (more than 1,100 deaths per day) in 2014 (Merai et al., 2016). The estimated healthcare and medical costs attributed to high BP amounted to $\$ 48.6$ billion annually (Merai et al., 2016). Major risk factors for high $\mathrm{BP}$ include unhealthy diet (e.g., eating foods with high sodium content and high saturated fat), and being obese, which is closely linked to diet and other lifestyle behaviours, such 
as physical activity (Li et al., 2009).

There is an increasing interest in examining neighbourhood contexts (e.g., food environments, such as the proximity of fastfood restaurants and supermarkets) that may play a key role in shaping these cardiovascular disease (CVD) risk factors (Diez Roux, 2003; Li et al., 2009; Leal and Chaix, 2011; Duncan and Kawachi, 2018). The existing research on neighbourhood environments in relation to CVD risk factors has focused almost exclusively on geopolitical administrative boundaries and geographic buffers around residential areas (Mujahid et al., 2008; Leal and Chaix, 2011; Stark et al., 2013; Kaiser et al., 2016). A systematic focus on residential areas and neighbourhoods defined by administrative units could lead to spatial misclassification (i.e. inappropriate assessment of the locations where individuals spend time) (Duncan et al., 2017). For instance, one review study on the effects of geographic environments on cardiometabolic risk indicated that $90 \%$ of 131 reviewed articles exclusively examined residential areas, $6 \%$ focused exclusively on non-residential environments, and only $4 \%$ considered both residential and non-residential environments (Leal and Chaix, 2011). The majority (65\%) of these reviewed studies used circular buffers with radii between 100 meters $(\mathrm{m})$ to $4800 \mathrm{~m}$ around residence and workplace, though some used network buffers, ranging from $640 \mathrm{~m}$ to $2000 \mathrm{~m}$ radius (Leal and Chaix, 2011). However, recent studies highlight the concept of spatial polygamy, in which individuals are generally mobile and so are exposed to multiple locations (e.g., home, work, shopping, socializing) in their daily lives (Matthews, 2011). Realtime geospatial methods, including Global Positioning System (GPS) technology, allow researchers to define more relevant neighbourhoods of exposure taking into account individuals' daily mobility (called activity spaces, defined as the network of places where individuals travel or move throughout a day and the trips between these places) (Zenk et al., 2011). These approaches are a rapidly developing methodology that can address limitations of exclusively assessing exposures around residential neighbourhoods with circular and network buffers in the field of food environment research and CVD risk (Boruff et al., 2012; Perchoux et al., 2013).

Studies applying GPS technologies have examined how neighbourhoods influence CVD relevant behavioural outcomes (i.e. physical activity and diet) (Zenk et al., 2011; Almanza et al., 2012; Rodríguez et al., 2012). For example, one study determined the density of fast-food restaurants using GPS-defined food environments based on daily path areas (i.e. buffering GPS monitoring points with a 0.5 mile radius and dissolving the entire areas to create one single feature (Zenk et al., 2011). A higher density of fast food restaurants was associated with higher consumption of saturated fat among a sample of adults in Detroit, Michigan (Zenk et al., 2011).

The importance of GPS methods lies in the fact that they measure activity spaces, minimizing spatial misclassification and overcoming the residential trap (i.e. restricting the information on exposure to residential areas) (Chaix, 2009; Duncan et al., 2017). Therefore, the purpose of this study was to explore the relevance of using GPS data for defining neighbourhoods to investigate the associations between neighbourhood food environments and both BMI and systolic and diastolic BP among a sample of low-income housing residents in NYC. In addition, we assessed mean density of food environment variables and population density around residential and GPS-defined activity space among this sample of adults. We hypothesized that higher densities of unhealthy food outlets (i.e. fast food restaurants and corner stores) would be associated with higher BMI and BP. In contrast, higher densities of healthy food outlets (i.e. wait service restaurants, grocery stores, and supermarkets) were hypothesized to be related to lower BMI and BP. We also anticipated that these associations may be strongly elucidated with the GPS-defined activity space, as opposed to residential circular and network buffers.

\section{Materials and Methods}

\section{Participants}

Data came from the NYC Low-Income Housing, Neighborhoods and Health Study $(\mathrm{N}=120)$ (Duncan et al., 2014). Low-income housing residents in NYC were recruited through outreach activities, such as handing out flyers around public housing developments in NYC, circulating flyers through community-based organizations, or via social networks. Eligibility criteria to participate in the present study included: i) residing in public housing or a low-income residence in NYC; ii) 18 years or older; iii) reading and speaking English; iv) not being pregnant; v) no walking limitations; and vi) willing to carry a GPS unit for one week. The majority $(80 \%)$ of our participants resided in public housing. Prior to data collection, we obtained informed consent from all participants. We collected the data in June through July 2014. The New York University School of Medicine Institutional Review Board reviewed and approved research procedures and study protocols. The previous studies have described further detailed data collection and procedures (Duncan et al., 2014; Duncan and Regan, 2015).

\section{Global positioning system and geographic information system data and processing}

Trained research assistants instructed participants in how to wear the GPS device (QStarz BT-Q1000XT GPS, Qstarz International Co., Ltd., Taipei, Taiwan). At the baseline assessment during the study orientation participants were asked to wear the device at all times for one week except while sleeping, bathing, or swimming. The protocol was adopted from a previous study (Duncan et al., 2016a). In a diary log, we asked the following question on a daily basis, "Did you charge the GPS monitor today?" Before deploying the GPS device, we programmed it to record at 30 -second intervals. After the data collection (participant wore the device for a week, charged it every day, and completed the diary), our research assistants met participants at public places or in our office to collect the devices.

After downloading the GPS data using a Qstarz software program, we created a geodatabase to manage and visualize the GPS data; we then stored the data using ArcGIS (ESRI Redlands, CA). We removed implausible GPS data (i.e. geographically isolated points) and data with date time-stamp errors, and with duplicated time-stamps, resulting in removal of five participants. Six out of 120 participants did not have GPS data because of battery problems, user error, or failure to return the device. Two participants lacked sufficient data (Duncan et al., 2014). Five participants travelled outside NYC and had the device with them for the majority of the time outside of NYC, and so were not included in the total sample. Thus, the total sample in this study comprised 102 participants. There are no statistically significant differences in the participants' characteristics between the current $(n=102)$ and the par- 
ticipants who were removed $(\mathrm{n}=18)$. The detailed data processing procedures have been described previously (Duncan et al., 2014).

\section{Food environments}

We created five objective food environment variables using ArcGIS 10.4 software (ESRI, Redland, CA). We used the data on all restaurants' locations (i.e. fast-food restaurants [national chain/non-chain outlets, defined as fast food with no indication of wait service] and wait-service restaurants [table service, and chain/non-chain outlets indicating any types of wait service outlet]) from the NYC Department of Health and Mental Hygiene Restaurant Grading data. Each restaurant or food outlet was in business by the end of 2014. All other food outlets' locations (i.e. corner stores [bodegas/convenience stores with less than 2,000 square feet], grocery stores [small/large groceries between 2,000 and 5,999 square feet], and supermarkets [classified as chain or independent supermarkets]) came from the New York State Department of Agriculture and Markets, Licensing and Inspection data. Density of each outlet type was based on the number of outlets divided by the total land area (square kilometers $\left[\mathrm{km}^{2}\right]$ ) for each buffer: densities of fast-food restaurants (unit: 10 outlets $/ \mathrm{km}^{2}$ ), wait-service restaurants (unit: 10 outlets $/ \mathrm{km}^{2}$ ), corner stores (unit: 10 outlets $/ \mathrm{km}^{2}$ ), grocery stores (unit: 1 outlet $/ \mathrm{km}^{2}$ ) and supermarkets (unit: 1 outlet $/ \mathrm{km}^{2}$ ).

A 200-meter $(\mathrm{m})$ and $400 \mathrm{~m}$ residential circular and line-based street network buffer was created around the geocoded home address of each participant (Figure 1) (Oliver et al., 2007). For the line-based network buffer, we created a $25 \mathrm{~m}$ buffer on both sides

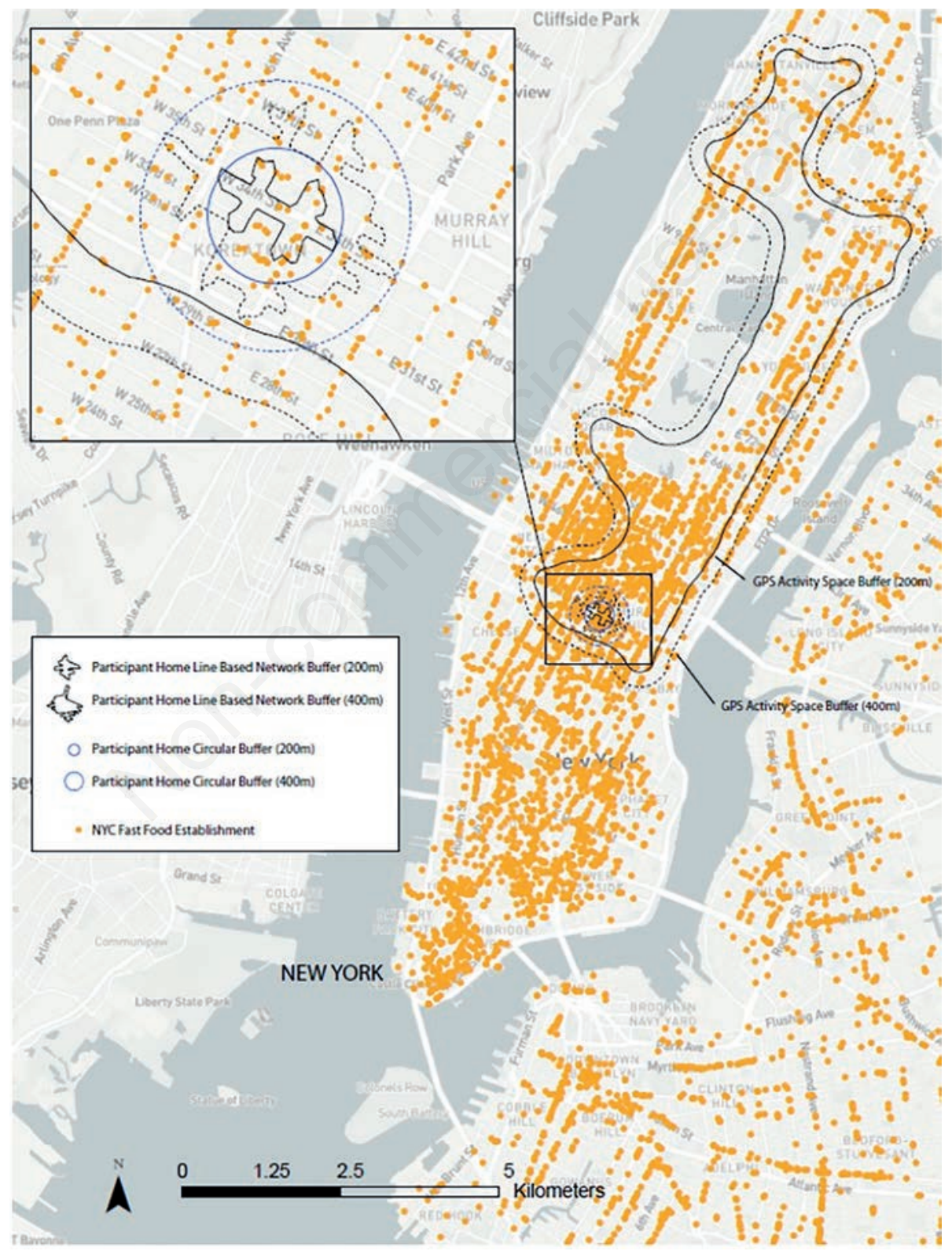

Figure 1. Locations of fast-food establishments (orange dots), residential buffers (circular and line-based network buffers), and GPS activity space buffers in New York City, 2014. Participant home line-based network buffer represent street network buffers around participant's home. Participant's home and the residential and GPS activity space buffers are based on hypothetical data. 
of the street to capture areas along the streets located within a 200 $\mathrm{m}$ or $400 \mathrm{~m}$ from the residences along the street network (Oliver et al., 2007). In addition, we created $200 \mathrm{~m}$ and $400 \mathrm{~m}$ buffers around participants' GPS-defined activity space (i.e. daily mobility path) derived from GPS data. This method has been used in behavioural geography to illustrate where people travel during the day and what they are exposed to in their neighbourhood environments (Tamura et al., 2017; Duncan and Kawachi, 2018). A recent review of studies on the food environment and GPS technology found that the size of buffers typically used for GPS-defined activity spaces (i.e. daily mobility path), for adult samples ranged from 0.25 ( $\sim 400$ $\mathrm{m})$ miles to 0.5 miles $(\sim 800 \mathrm{~m})$ (Cetateanu and Jones, 2016). Consistent with our prior studies (Duncan et al., 2017; Tamura et al., 2017), we chose a $200 \mathrm{~m}$ and $400 \mathrm{~m}$ radius for the GPS-defined activity space buffer, because our interests are immediate food environment exposures (i.e. walkable distance) around the locations where participants travel and move throughout a day.

\section{Body mass index and blood pressure}

Our trained research staff used a Tanita 351 scale to measure participants' heights and weights, which were then used to compute BMI (weight in $\mathrm{kg} /$ height in $\mathrm{m}^{2}$ ). To measure their BP, we had our participants sit in a chair without crossing their legs, while their arms were extended for the measurement of BP for about 1530 seconds (Hess et al., 2007; Ravenell et al., 2013; Duncan et al., 2016b; Tamura et al., 2017). Subsequently, our staff assessed systolic and diastolic BP (based on $\mathrm{mmHg}$ ) with a Welch Allyn Vital Signs 300 monitor (https://www.welchallyn.com/en/products/categories/patient-monitoring/vital-signs-devices/vital-signs-monitor300-series.html).

\section{Covariates}

Covariates included: age (18-24, 25-44, and 45 years and older), gender (male, female), race/ethnic groups (Black, Hispanic, and Other [White, Asian, and other]), education ( $<$ high school vs. $\geq$ high school), employment (unemployed, part-time, or full-time), and total household income $(<\$ 25,000, \$ 25,000-\$ 49,999, \geq$ $\$ 50,000)$. To control for populous areas in NYC, we calculated population density (using U.S. Census 2010 at the census block level), defined as the number of population divided by the total area $\left(\mathrm{km}^{2}\right)$ for each size (i.e. $200 \mathrm{~m}$ and $400 \mathrm{~m}$ ) and type of buffer (i.e. residential circular, residential network, and GPS-defined activity space buffers) (Tamura et al., 2017). Further, to account for neighbourhood effects by socio-demographic groups, we included percentage of non-Hispanic Black residents and median household income at the census block group level.

\section{Statistical analysis}

We used ordinary least square to investigate relationships between GIS-measured food environment attributes (i.e. densities of fast-food restaurants, wait-service restaurants, corner stores, grocery stores, and supermarkets) and BMI and systolic and diastolic $\mathrm{BP}$, clustered by census block group with robust standard errors, using PROC SURVEYREG in SAS version 9.4 (Cary, NC, USA). All the analyses were controlled for clustering effect at the census block group with clustered robust standard errors. Further, we tested for non-linearity of the relationships by adding a quadratic term in the models. These associations were separately investigated for each $200 \mathrm{~m}$ and $400 \mathrm{~m}$ residential circular and network buffers around respondents' home addresses with respect to each food out- let type, as well as for each $200 \mathrm{~m}$ and $400 \mathrm{~m}$ GPS-defined activity space. Our modelling strategy employed a two-step process. For example, in Model 1 we examined the relationship between the density of fast-food restaurants around residences with a $200 \mathrm{~m}$ circular buffer, controlling for individuals' demographics (i.e. age, gender, race/ethnicity groups, education attainment level, employment, and total household income at the individual level). In Model 2, we examined the relationship between the density of fast-food restaurants around residences with a $200 \mathrm{~m}$ circular buffer, controlling for other food outlets together (i.e. in this case with four other food outlets with a $200 \mathrm{~m}$ circular buffer) and neighbourhood demographic characteristics (i.e. percent of non-Hispanic Black and median household income at the census block group, and population density within each buffer) in addition to the individual demographic variables aforementioned in Model 1.

\section{Results}

\section{Individual and neighbourhood characteristics}

We summarized all the study variables in Table 1 . The mean participant age was 39.3 ( $\mathrm{SD} \pm 14.1$ ) years. Forty-eight percent of participants were female and the majority $(69 \%)$ were either Black or Hispanic (chi-squared test, $\mathrm{P}<.0001$ ) (Table 1). Roughly one third of participants had some college education. The majority of the participants earned less than $\$ 25,000$ a year $(72 \%)(\mathrm{P}<.0001)$ and were unemployed $(57 \%)(\mathrm{P}<.0001)$. On average, participants had $\mathrm{BMI}=29.8(\mathrm{SD} \pm 7.95)$, systolic $\mathrm{BP}=130.9(\mathrm{SD} \pm 17.9)$, and diastolic $\mathrm{BP}=77.7(\mathrm{SD} \pm 12.2)$. The mean census block group percent of non-Hispanic Blacks and household income were 31.5 $(\mathrm{SD} \pm 21.3)$ and $\$ 44,003(\mathrm{SD} \pm 28,030)$, respectively.

\section{Mean density of food environment variables and popu- lation density}

Overall, each food outlet type and population density around residential areas is higher than those of the GPS activity space buffers (Table 2 and Figure 1). Furthermore, among GPS activity space buffers, densities were systematically higher in $200 \mathrm{~m}$ than in $400 \mathrm{~m}$ buffers. For example, mean density of fast-food restaurants ranged from 116.2 per square kilometer $\left(\mathrm{km}^{2}\right)(\mathrm{SD} \pm 53.5)$ with a $400 \mathrm{~m}$ GPS-defined activity space buffer to $172.8 / \mathrm{km}^{2}$ $(\mathrm{SD} \pm 191.3)$ with a $200 \mathrm{~m}$ network buffer. Population density was the highest with the $200 \mathrm{~m}$ circular buffer $\left(37,719\right.$ people $\left./ \mathrm{km}^{2}\right)$ and the lowest with the $400 \mathrm{~m}$ GPS-defined buffer $(25,787$ people $/ \mathrm{km}^{2}$ ).

\section{Associations between the food environment and body mass index}

Overall, higher densities of food outlets are associated with lower BMI in Model 1 (i.e. adjusting for individual-level demographic characteristics), except for corner stores (Table 3). For example, in Model 1, considering a $400 \mathrm{~m}$ residential circular buffer, a higher fast-food restaurant density (i.e. a 10-outlets $/ \mathrm{km}^{2}$ increase) was associated with a lower BMI $\left(\beta=-0.2 \mathrm{~kg} / \mathrm{m}^{2} ; 95 \%\right.$ Confidence Interval $[\mathrm{CI}]=-0.3,-0.1$ ), and a higher supermarket density (a 1-outlet $/ \mathrm{km}^{2}$ increase) was associated with lower BMI $\left(\beta=-0.34 \mathrm{~kg} / \mathrm{m}^{2} ; 95 \% \mathrm{CI}=-0.54,-0.13\right)$. A higher grocery store density was consistently associated with lower BMI (Range: $\beta=-0.08$ to -0.19 ) with residential circular and network buffers. However, 
the majority of the fully-adjusted models (Model 2) did not reach statistical significance, except for grocery stores $\left(\beta=-0.20 \mathrm{~kg} / \mathrm{m}^{2}\right.$; $95 \% \mathrm{CI}=-0.40,0.00$, marginally significant, $\mathrm{P}=0.0054)$ within the $400 \mathrm{~m}$ network buffer. Generally, the overall model fit $\left(\mathrm{R}^{2}\right)$ improved from Model 1 (range: 0.20-0.27) to Model 2 (range: 0.24-0.29) (Table 3).

\section{Associations between the food environment and systolic and diastolic blood pressure}

Overall, higher densities of all five food outlets were associated with lower systolic BP in Model 1 (Table 4). However, only a higher grocery store density remained statistically significant in the fully adjusted models, which was associated with lower systolic BP for the circular and network buffers, as well as for the density of supermarkets within a $400 \mathrm{~m}$ circular buffer. For example, in the fully adjusted model (Model 2), a higher grocery store density (1-outlet $/ \mathrm{km}^{2}$ increase) was associated with lower systolic BP within a $400 \mathrm{~m}$ residential network buffer $(\beta=-0.78 \mathrm{mmHg}$; $95 \% \mathrm{CI}=-1.23,-0.34, \mathrm{P}=0.0009)$. In contrast, higher supermarket density (1-outlet $/ \mathrm{km}^{2}$ increase) was associated with higher systolic BP within a $400 \mathrm{~m}$ residential circular buffer $(\beta=1.73 \mathrm{mmHg}$; $95 \% \mathrm{CI}=0.21,3.25], \mathrm{P}=0.027)$. No relationships were documented in the fully-adjusted models with systolic BP between fast-food restaurants, wait-service restaurants, and corner stores for $200 \mathrm{~m}$ and $400 \mathrm{~m}$ residential circular buffers, residential network buffers, and GPS-defined activity space buffers.

Higher densities of fast-food restaurants, wait-service outlets, grocery stores, and supermarkets were associated with lower diastolic BP in Model 1 with the residential circular and network and with the GPS activity space buffers. In the fully adjusted models (Model 2), a higher grocery store density (1-outlet $/ \mathrm{km}^{2}$ increase) was associated with lower diastolic BP within the $400 \mathrm{~m}$ residential circular $(\beta=-1.02 \mathrm{mmHg} ; 95 \% \mathrm{CI}=-1.61,-0.43, \mathrm{P}=0.0012)$ and $400 \mathrm{~m}$ residential network buffers $(\beta=-0.58 \mathrm{mmHg}$; $95 \% \mathrm{CI}=-0.88$, $-0.29, \mathrm{P}=0.0003$ ), but not within the $200 \mathrm{~m}$ GPS activity space buffers. A higher supermarket density (1-outlet $/ \mathrm{km}^{2}$ increase) was associated with higher diastolic BP within a $400 \mathrm{~m}$ residential circular buffer $(\beta=1.67 \mathrm{mmHg} ; 95 \% \mathrm{CI}=0.52,2.83, \mathrm{P}=0.0054)$. Although we tested for non-linearity of the models with a quadratic term, most of them were not significant. For both systolic and diastolic BP, the overall model fit $\left(\mathrm{R}^{2}\right)$ improved from Model 1 to Model 2 (Tables 4 and 5).

\section{Discussion}

The present study investigated associations of density of food environments around residential areas and GPS-defined activity space with BMI and systolic and diastolic BP among a sample of low-income-housing residents in NYC. Overall, in the fully adjust-

Table 1. Individual demographic and health-related characteristics, and census-block group characteristics of participants $(n=102)$.

\begin{tabular}{|c|c|c|}
\hline Individual characteristics & n (\%) & $\mathbf{P}^{c}$ \\
\hline $\begin{array}{l}\text { Age groups } \\
\text { 18-24 years } \\
25-44 \text { years } \\
45+\text { years }\end{array}$ & $\begin{array}{l}23(22.55) \\
37(36.27) \\
42(41.18)\end{array}$ & 0.0577 \\
\hline $\begin{array}{l}\text { Gender } \\
\quad \text { Male } \\
\text { Female }\end{array}$ & $\begin{array}{l}49(48.04) \\
53(51.96)\end{array}$ & 0.6921 \\
\hline $\begin{array}{l}\text { Race/ethnicity }^{\mathrm{a}} \\
\text { Black } \\
\text { Hispanic } \\
\text { Other (White, Asian and other) }\end{array}$ & $\begin{array}{c}69(69.00) \\
22(22.00) \\
9(9.00)\end{array}$ & $<.0001$ \\
\hline $\begin{array}{l}\text { Education } \\
<\text { High school } \\
\text { High school graduate } \\
\text { Some college or more }\end{array}$ & $\begin{array}{l}27(26.47) \\
44(43.14) \\
31(30.39)\end{array}$ & 0.0979 \\
\hline $\begin{array}{l}\text { Total household income }{ }^{\mathrm{a}} \\
\quad<\$ 25,000 \\
\quad \$ 25,000-\$ 49,999 \\
\geq \$ 50,000\end{array}$ & $\begin{array}{c}73(72.28) \\
21(20.79) \\
7(6.93)\end{array}$ & $<.0001$ \\
\hline $\begin{array}{l}\text { Employment status }^{\mathrm{a}} \\
\text { Full-time } \\
\text { Part-time } \\
\text { Unemployed } \\
\text { Retired or school }\end{array}$ & $\begin{array}{l}13(13.00) \\
18(18.00) \\
57(57.00) \\
12(12.00)\end{array}$ & $<.0001$ \\
\hline
\end{tabular}

Body mass index

$29.84(7.95)$

$\begin{array}{lc}\text { Blood pressure (mmhg) } & \\ \text { Systolic } & 130.90(17.90) \\ \text { Diastolic } & 77.73(12.23)\end{array}$

Census block group demographic characteristics \% non-Hispanic Black $31.50(21.26)$ Household income $44,003(28,029)$

Analytic sample ( $\mathrm{N}=102)$ is based on when outcomes are no missing. ${ }^{\text {Race/ethnicity, total household }}$ income, employment status are missing with 2, 1, and 2 participants, respectively; 'SD: Standard Deviation; ${ }^{\mathrm{P}} \mathrm{P}-\mathrm{value}$ was based on Chi-square test for categorical variables.

Table 2. Mean density of food environment variables and population density around home and global positioning system defined activity space neighborhoods among 102 participants in 2014.

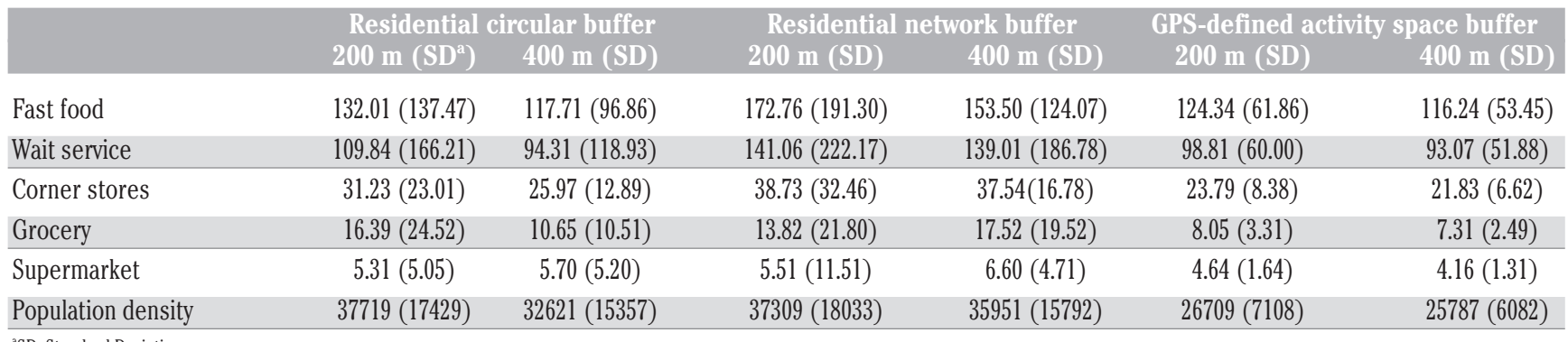

asD: Standard Deviation. 
ed models, almost all five of the built environment variables are not associated with BMI and systolic and diastolic BP, with a few exceptions for grocery stores and supermarkets. Specifically, a higher grocery store density within $200 \mathrm{~m}$ network buffer was related to lower BMI (with 200 m network buffer) and BP with both circular and network buffers. A higher supermarket density was associated with higher systolic and diastolic BP. Associations between GPS-defined food environments and BMI and BP are mostly null.

The total areas of an individual's activity space are generally bigger compared to residential buffers around homes (e.g., $200 \mathrm{~m}$ circular buffer), implying that individuals move beyond their residential areas on a daily basis. Also, our food outlet densities differed by types of buffers (e.g., $200 \mathrm{~m}$ residential circular and network buffers for fast-food outlets: 132.1 outlets $/ \mathrm{km}^{2}$ and $172.8 / \mathrm{km}^{2}$ vs $200 \mathrm{~m}$ GPS activity space: $124.7 / \mathrm{km}^{2}$ ). Our findings on residential and GPS activity space food environments suggest that the residential and the food environment landscape in NYC is unique, specifically within the low-income housing communities. Contrary to our findings, a recent study investigating the distance to food purchasing locations from home in Melbourne, Australia, found that the median distance from which participants purchased foods was $3.6 \mathrm{~km}$ (Thornton et al., 2017). Our findings may also suggest that the neighbourhoods in NYC are relatively well represented by residential circular or network buffers, compared to GPS-defined activity space. Yet, this is attributed to NYC because of its density of development and preponderance of mixed use development. Therefore, further research is needed to utilize both residential and GPS activity space buffers to determine the food environments in relation to $\mathrm{BMI}$ and $\mathrm{BP}$, because most previous studies only used residential areas to quantify the environmental exposures. As discussed, people generally move and travel during their day-to-day activities. Thus, both residential areas and locations where people travel throughout a day are crucial to better understand how the food environments may be associated with BMI and BP among adults.

There may be several reasons for the findings from our study. First, other studies examined more proximal relationships (i.e. food environments and certain food consumptions; Zenk et al., 2011; Christian, 2012; Shearer et al., 2015) compared to ours (i.e. food environments and BMI/BP). As our linkages are more distal, other factors, such as food preparation and physical activity could also influence increase and decrease in BMI and BP. Second, previous studies among adult samples used larger buffers (e.g., 0.5 miles, equivalent to $800 \mathrm{~m}$ ) around GPS activity space (Zenk et al., 2011; Christian, 2012), which may capture a greater number of

Table 3. Relationships between food environments and body mass index among 102 participants.

\begin{tabular}{|c|c|c|c|c|c|c|c|}
\hline & & $\beta$ & $\begin{array}{l}\text { Model 1 }{ }^{\mathrm{a}} \\
95 \% \text { C.I. }\end{array}$ & $\mathbf{R}^{2}$ & $\beta$ & $\begin{array}{l}\text { Model } 2^{\mathrm{b}} \\
95 \% \text { C.I. }\end{array}$ & $\mathbf{R}^{2 \mathrm{~g}}$ \\
\hline Fast food (10 outlets/km²) & $\begin{array}{l}200 \mathrm{~m} \text { circular }^{\mathrm{d}} \\
400 \mathrm{~m} \text { circular }^{\mathrm{m}} \\
200 \mathrm{~m} \text { network } \\
400 \mathrm{~m} \text { network } \\
200 \mathrm{~m} \mathrm{GPS}^{\mathrm{f}} \\
400 \mathrm{~m} \text { GPS }\end{array}$ & $\begin{array}{r}-0.14^{* * *} \\
-0.20^{* * *} \\
-0.09 * * * \\
-0.15^{* * *} \\
-0.22 \\
-0.22\end{array}$ & $\begin{array}{l}-0.21,-0.07 \\
-0.30,-0.10 \\
-0.13,-0.04 \\
-0.23,-0.08 \\
-0.47,0.03 \\
-0.50,0.05\end{array}$ & $\begin{array}{l}0.25 \\
0.25 \\
0.24 \\
0.25 \\
0.23 \\
0.22\end{array}$ & $\begin{array}{r}-0.22 \\
-0.15 \\
0.01 \\
0.09 \\
-0.52 \\
-0.53\end{array}$ & $\begin{array}{l}-0.60,0.15 \\
-0.47,0.17 \\
-0.21,0.22 \\
-0.28,0.46 \\
-1.96,0.93 \\
-2.06,1.00\end{array}$ & $\begin{array}{l}0.28 \\
0.26 \\
0.29 \\
0.29 \\
0.24 \\
0.24\end{array}$ \\
\hline Wait service (10 outlets/km²) & $\begin{array}{l}200 \text { m circular } \\
400 \text { m circular } \\
200 \text { m network } \\
400 \text { m network } \\
200 \text { m GPS } \\
400 \text { m GPS }\end{array}$ & $\begin{array}{r}-0.11 * * * \\
-0.15 * * * \\
-0.07 * * * \\
-0.10 * * * \\
-0.19 \\
-0.19\end{array}$ & $\begin{array}{l}-0.16,-0.06 \\
-0.23,-0.08 \\
-0.11,-0.08 \\
-0.15,-0.05 \\
-0.43,0.06 \\
-0.49,0.11\end{array}$ & $\begin{array}{l}0.25 \\
0.25 \\
0.24 \\
0.25 \\
0.22 \\
0.21\end{array}$ & $\begin{array}{l}0.24 \\
0.13 \\
0.07 \\
0.10 \\
0.40 \\
0.42\end{array}$ & $\begin{array}{l}-0.15,0.62 \\
-0.25,0.51 \\
-0.09,0.22 \\
-0.13,0.32 \\
-1.22,2.03 \\
-1.39,2.23\end{array}$ & $\begin{array}{l}0.28 \\
0.26 \\
0.29 \\
0.29 \\
0.24 \\
0.24\end{array}$ \\
\hline Corner store $\left(10\right.$ outlets $\left./ \mathrm{km}^{2}\right)$ & $\begin{array}{l}200 \text { m circular } \\
400 \text { m circular } \\
200 \text { m network } \\
400 \text { m network } \\
200 \text { m GPS } \\
400 \text { m GPS }\end{array}$ & $\begin{array}{l}-0.49 \\
-0.52 \\
-0.14 \\
-0.80 \\
-0.52 \\
-1.02\end{array}$ & $\begin{array}{l}-1.29,0.31 \\
-1.97,0.92 \\
-0.56,0.27 \\
-1.65,0.04 \\
-2.62,1.58 \\
-3.48,1.45\end{array}$ & $\begin{array}{l}0.22 \\
0.21 \\
0.20 \\
0.23 \\
0.20 \\
0.21\end{array}$ & $\begin{array}{r}0.39 \\
0.46 \\
-0.12 \\
-0.28 \\
-0.07 \\
-0.56\end{array}$ & $\begin{array}{l}-0.54,1.33 \\
-1.18,2.09 \\
-0.61,0.38 \\
-1.43,0.88 \\
-3.35,3.22 \\
-3.46,2.35\end{array}$ & $\begin{array}{l}0.28 \\
0.26 \\
0.29 \\
0.29 \\
0.24 \\
0.24\end{array}$ \\
\hline Grocery store (1 outlet/km²) & $\begin{array}{l}200 \text { m circular } \\
400 \text { m circular } \\
200 \text { m network } \\
400 \text { m network } \\
200 \text { m GPS } \\
400 \text { m GPS }\end{array}$ & $\begin{array}{r}-0.08 * * * \\
-0.19 * * * \\
-0.10 * * * \\
-0.12 * * * \\
-0.27 \\
-0.37\end{array}$ & $\begin{array}{l}-0.12,-0.04 \\
-0.29,-0.09 \\
-0.14,-0.06 \\
-0.17,-0.07 \\
-0.59,0.06 \\
-0.82,0.08\end{array}$ & $\begin{array}{l}0.25 \\
0.26 \\
0.27 \\
0.27 \\
0.21 \\
0.21\end{array}$ & $\begin{array}{r}-0.11 \\
-0.16 \\
-0.12 * \\
-0.20 \\
0.23 \\
0.60\end{array}$ & $\begin{array}{r}-0.30,0.09 \\
-0.56,0.25 \\
-0.22,-0.02 \\
-0.40,0.00 \\
-0.73,1.19 \\
-1.29,2.49\end{array}$ & $\begin{array}{l}0.28 \\
0.26 \\
0.29 \\
0.29 \\
0.24 \\
0.24\end{array}$ \\
\hline Supermarket (1 outlet/km²) & $\begin{array}{l}200 \mathrm{~m} \text { circular } \\
400 \mathrm{~m} \text { circular } \\
200 \mathrm{~m} \text { network } \\
400 \mathrm{~m} \text { network } \\
200 \mathrm{~m} \text { GPS } \\
400 \mathrm{~m} \text { GPS }\end{array}$ & $\begin{array}{r}-0.33^{*} \\
-0.34^{* *} \\
-0.04 \\
-0.34 \\
-0.67 \\
-0.93^{*}\end{array}$ & $\begin{array}{l}-0.65,-0.01 \\
-0.54,-0.13 \\
-0.18,0.10 \\
-0.69,0.01 \\
-1.36,0.01 \\
-1.76,-0.10 \\
\end{array}$ & $\begin{array}{l}0.24 \\
0.24 \\
0.24 \\
0.23 \\
0.22 \\
0.22 \\
\end{array}$ & $\begin{array}{l}-0.21 \\
-0.02 \\
-0.08 \\
-0.05 \\
-0.45 \\
-0.81 \\
\end{array}$ & $\begin{array}{l}-0.61,0.18 \\
-0.80,0.76 \\
-0.25,0.08 \\
-0.54,0.43 \\
-2.50,1.60 \\
-4.29,2.67\end{array}$ & $\begin{array}{l}0.28 \\
0.26 \\
0.29 \\
0.29 \\
0.24 \\
0.24\end{array}$ \\
\hline
\end{tabular}

Statistical significance based on ${ }^{* *} \mathrm{P}<0.001 ;{ }^{* *} \mathrm{P}<0.01 ; * \mathrm{P}<0.05$. ${ }^{\text {a }}$ Model 1 controlled for individual demographics; ${ }^{\mathrm{b}}$ Model 2 fully-adjusted for individual demographics, neighbourhood demographic characteristics and population density, and other food environment variables; ${ }^{\mathrm{c}} \mathrm{C} . \mathrm{I}$.: Confidence Interval; ${ }^{\mathrm{d}}$ Residential circular buffer; ${ }^{\mathrm{e}}$ Residential network buffer; ${ }^{\mathrm{f}} \mathrm{GPS}$-defined activity space buffer; ${ }^{\circ}$ Model $2 \mathrm{R}^{2}$ values are presented the same for each food outlet, as all five food outlets variables are adjusted. 
food stores within the buffers, compared to our food outlet measures using $200 \mathrm{~m}$ and $400 \mathrm{~m}$ buffers around GPS activity space. Our participants residing in low-income housing may seek out foods near and around their residences compared to areas away from home (i.e. GPS activity space), as we did not observe any statistically significant associations using GPS activity space, but for residential buffers. The rationale for our buffer size is that NYC is highly populous and has more stores in the city compared to other urban areas (e.g., Lexington, Kentucky (Christian, 2012) and Detroit, Michigan (Zenk et al., 2011) in the U.S. These differences in size of buffers could potentially influence our results.

Our findings of inverse and positive relationships between food outlets (grocery stores, fast food outlets) and BP are inconsistent with the findings from previous studies on food outlet-access in relation to BP (Morland et al., 2006; Li et al., 2009; Dubowitz et al., 2012). For example, one study examined associations of supermarkets, grocery stores, and convenience stores at the census tract level with hypertension among 10,763 men and women participants from Mississippi, North Carolina, Maryland, and Minnesota. They found that only a higher density of grocery stores within the census tract where participants reside was related to greater prevalence of hypertension in the fully adjusted models. However, no associations were reported for supermarkets and convenience stores (Morland et al., 2006). Another study investigating changes in neighbourhood environments and BP among 1,145 middle-aged and older adults found that high density of fast-food restaurants in low walkable neighbourhoods was related to an increase in BP over time (Li et al., 2009). Furthermore, higher density of supermarkets within a 1.5 mile buffer around residences was associated with lower diastolic BP among 60,775 middle-aged and older women (Dubowitz et al., 2012). Contrary to our hypothesis, a higher density of supermarkets around the residential areas was associated with higher systolic and diastolic BP in the current study. However, consistent with the findings from the previous study, the presence of a supermarket near a residential area was associated with higher BMI among children (Fiechtner et al., 2013). One potential explanation is that having a higher density of supermarkets around residential areas could lead to the purchase of more high caloric foods (Aktas Arnas, 2006). Additionally, the high price of healthy foods may be related to participants' purchasing unhealthy foods at a supermarket nearby.

Generally, the directions of associations between grocery stores and weight status are mixed. For example, a study on grocery stores found that women participating in the WIC program in Kansas (Ford and Dzewaltowski, 2010) who had grocery stores within 1 mile of their home addresses had higher odds of being obese. In contrast, another study found that having mid-size grocery stores within 1 mile of homes was related to lower odds of

Table 4. Relationships between food environments and systolic blood pressure among 102 participants.

\begin{tabular}{|c|c|c|c|c|c|c|c|}
\hline & & $\beta$ & $\begin{array}{l}\text { Model 1 }{ }^{\mathrm{a}} \\
95 \% \text { C.I. }\end{array}$ & $\mathbf{R}^{2}$ & $\beta$ & $\begin{array}{l}\text { Model 2 } \\
95 \% \text { C.I. }\end{array}$ & $\mathbf{R}^{2} \mathrm{~g}$ \\
\hline Fast food (10 outlets/km²) & $\begin{array}{l}200 \text { m circular }^{\mathrm{d}} \\
400 \mathrm{~m} \text { circular } \\
200 \mathrm{~m}^{\mathrm{n}} \text { etwork } \\
400 \mathrm{~m} \text { network } \\
200 \mathrm{~m} \mathrm{GPS}^{\mathrm{f}} \\
400 \mathrm{~m} \text { GPS }\end{array}$ & $\begin{array}{r}-0.22 \\
-0.30 \\
-0.13^{*} \\
-0.24 \\
-0.57^{*} \\
-0.60^{*}\end{array}$ & $\begin{array}{l}-0.44,0.00 \\
-0.64,0.04 \\
-0.26,-0.00 \\
-0.48,0.01 \\
-1.08,-0.06 \\
-1.16,-0.05\end{array}$ & $\begin{array}{l}0.18 \\
0.18 \\
0.18 \\
0.18 \\
0.19 \\
0.19\end{array}$ & $\begin{array}{r}0.61 \\
0.76 \\
0.01 \\
0.32 \\
-0.32 \\
0.37\end{array}$ & $\begin{array}{l}-0.51,1.74 \\
-0.33,1.84 \\
-0.68,0.71 \\
-0.78,1.41 \\
-2.81,2.17 \\
-2.24,2.99\end{array}$ & $\begin{array}{l}0.25 \\
0.27 \\
0.23 \\
0.26 \\
0.24 \\
0.23\end{array}$ \\
\hline Wait service (10 outlets/km²) & $\begin{array}{l}200 \text { m circular } \\
400 \text { m circular } \\
200 \text { m network } \\
400 \text { m network } \\
200 \text { m GPS } \\
400 \text { m GPS }\end{array}$ & $\begin{array}{c}-0.20^{* *} \\
-0.25^{*} \\
-0.12^{*} \\
-0.16^{*} \\
-0.53^{*} \\
-0.63^{*}\end{array}$ & $\begin{array}{l}-0.35,-0.06 \\
-0.47,-0.04 \\
-0.22,-0.02 \\
-0.28,-0.03 \\
-0.98,-0.09 \\
-1.13,-0.13 \\
\end{array}$ & $\begin{array}{l}0.19 \\
0.19 \\
0.18 \\
0.18 \\
0.19 \\
0.19\end{array}$ & $\begin{array}{r}0.20 \\
-0.42 \\
0.11 \\
0.39 \\
-0.38 \\
-1.36\end{array}$ & $\begin{array}{l}-0.68,1.08 \\
-1.62,1.84 \\
-0.45,0.67 \\
-0.26,1.03 \\
-3.18,2.41 \\
-4.40,1.67\end{array}$ & $\begin{array}{l}0.25 \\
0.27 \\
0.23 \\
0.26 \\
0.24 \\
0.23\end{array}$ \\
\hline Corner store (10 outlets/km²) & $\begin{array}{l}200 \text { m circular } \\
400 \text { m circular } \\
200 \text { m network } \\
400 \text { m network } \\
200 \text { m GPS } \\
400 \text { m GPS }\end{array}$ & $\begin{array}{r}-1.23 \\
-1.34 \\
0.21 \\
-0.58 \\
-3.04^{*} \\
-3.30\end{array}$ & $\begin{array}{r}-3.07,0.62 \\
-4.03,1.35 \\
-0.80,1.22 \\
-2.70,1.54 \\
-5.81,-0.28 \\
-6.77,0.16\end{array}$ & $\begin{array}{l}0.18 \\
0.17 \\
0.16 \\
0.16 \\
0.18 \\
0.17\end{array}$ & $\begin{array}{r}-0.69 \\
-0.08 \\
-0.001 \\
0.41 \\
-3.22 \\
-5.78\end{array}$ & $\begin{array}{l}-3.12,1.74 \\
-4.25,4.10 \\
-1.02,1.02 \\
-2.60,3.42 \\
-8.56,2.12 \\
-12.22,0.65\end{array}$ & $\begin{array}{l}0.25 \\
0.27 \\
0.23 \\
0.26 \\
0.24 \\
0.23\end{array}$ \\
\hline Grocery store (1 outlet/km²) & $\begin{array}{l}200 \text { m circular } \\
400 \text { m circular } \\
200 \text { m network } \\
400 \text { m network } \\
200 \text { m GPS } \\
400 \text { m GPS }\end{array}$ & $\begin{array}{r}-0.18^{* * *} \\
-0.42^{* *} \\
-0.15^{*} \\
-0.23^{* * *} \\
-1.11^{* *} \\
-1.34^{*}\end{array}$ & $\begin{array}{l}-0.26,-0.09 \\
-0.67,-0.17 \\
-0.28,-0.03 \\
-0.34,-0.11 \\
-1.88,-0.34 \\
-2.34,-0.33\end{array}$ & $\begin{array}{l}0.21 \\
0.21 \\
0.19 \\
0.21 \\
0.20 \\
0.19\end{array}$ & $\begin{array}{r}-0.55^{*} \\
-1.16^{* *} \\
-0.24 \\
-0.78 * * * \\
-0.20 \\
0.94\end{array}$ & $\begin{array}{r}-1.08,-0.02 \\
-1.89,-0.42 \\
-0.60,0.11 \\
-1.23,-0.34 \\
-2.67,2.27 \\
-4.06,5.96\end{array}$ & $\begin{array}{l}0.25 \\
0.27 \\
0.23 \\
0.26 \\
0.24 \\
0.23\end{array}$ \\
\hline Supermarket (1 outlet/km²) & $\begin{array}{l}200 \text { m circular } \\
400 \text { m circular } \\
200 \text { m network } \\
400 \text { m network } \\
200 \text { m GPS } \\
400 \text { m GPS }\end{array}$ & $\begin{array}{r}-0.44 \\
-0.41 \\
-0.14 \\
-0.35 \\
-1.69 \\
-2.50 * \\
\end{array}$ & $\begin{array}{l}-1.22,0.33 \\
-1.08,0.26 \\
-0.53,0.24 \\
-1.26,0.55 \\
-3.40,0.02 \\
-4.85,-0.16\end{array}$ & $\begin{array}{l}0.17 \\
0.17 \\
0.17 \\
0.17 \\
0.18 \\
0.19\end{array}$ & $\begin{array}{r}-0.08 \\
1.73^{*} \\
-0.28 \\
0.33 \\
2.53 \\
0.74 \\
\end{array}$ & $\begin{array}{r}-1.07,0.91 \\
0.21,3.25 \\
-0.70,0.15 \\
-0.83,1.49 \\
-2.16,7.23 \\
-10.01,11.50\end{array}$ & $\begin{array}{l}0.25 \\
0.27 \\
0.23 \\
0.26 \\
0.24 \\
0.23\end{array}$ \\
\hline
\end{tabular}

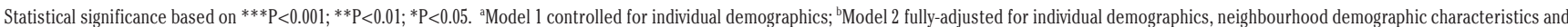
population density, and other food environment variables; ${ }^{\mathrm{C}}$.I.: Confidence Interval; ${ }^{d}$ Residential circular buffer; ${ }^{\text {R }}$ Residential network buffer; ${ }^{\prime} \mathrm{GPS}$-defined activity space buffer; ${ }^{\circ} \mathrm{Model} 2 \mathrm{R}^{2}$ values are presented the same for each food outlet, as all five food outlets variables are adjusted. 
being obese among California adults (Hattori et al., 2013). Consistent with the previous study on inverse relationships between grocery stores and BMI among adults aged 25-64 (Zick et $a l ., 2009$ ), our study also found inverse associations between grocery stores around residential areas and BMI, which we hypothesized (i.e. a higher grocery stores density linked to lower BMI). One possible explanation is that those living in low-income neighbourhoods and housing residents may shop for healthy foods at grocery stores within an immediate neighbourhood. These findings show that having access to grocery stores around residential areas could be related to weight status among low-income residents.

There are several limitations to be addressed. The present study has a cross-sectional design; therefore, causal inferences cannot be made from these data. The findings from the present study cannot be generalized to populations that come from high or middle-income families in NYC, who reside in suburbs or rural areas of the U.S., or who are non-English-speaking residents. BP was measured only once by our research staff. However, in a clinical BP assessment, it is generally required to be measured two or more times, while discarding the first measurement. Therefore, measurement error of BP in our sample may be possible due to just a single BP measurement. Some GPS coordinates may not be recorded because skyscraper buildings in a city like NYC, may impede GPS satellite signals. Our study made efforts to address confounding, by controlling for population density and neighbourhood socioeconomic status. We adjusted for population density because the density of food stores is connected to the degree of urbanicity in the neighbourhood, which is itself related to other potential determinants of metabolic health. However, there may be residual confounding, for example, by other food outlets, or aggregate indices, such as the Modified Retail Food Environment Index (i.e. indicator of healthy and unhealthy retail ratio in each census tract) (Gustafson et al., 2012), or even by the physical activity opportunities (e.g., sport facilities) around residential areas and GPS activity space, which we did not measure in our study. Other sources of confounding are related to selective residential migration and selective daily mobility biases (Chaix et al., 2013a; Chaix et al., 2013b). The first is related to the existence of dietary preferences that would lead residents to live in specific neighbourhoods (as a confounder for the identified residential association) and the second to the preferences for specific foods leading participants to visit specific outlets during the GPS follow-up and therefore biasing our GPS activity space exposure variables. Our GPS activity space buffers may include locations such as rivers (e.g., Hudson, East River), which might lead to decreased positive predictive value in our estimates. However, this may be minimal, because our sizes of GPS activity space (i.e. $200 \mathrm{~m}$ and $400 \mathrm{~m}$ ) are smaller than those of previous studies ( 0.5 miles is about $800 \mathrm{~m}$ ) (Zenk et al.,

Table 5. Relationships between food environments and diastolic blood pressure among 102 participants.

\begin{tabular}{|c|c|c|c|c|c|c|c|}
\hline & & & Model $1^{\mathrm{a}}$ & & & Model $2^{b}$ & \\
\hline & & $\beta$ & 95\% C.I. ${ }^{c}$ & $\mathbf{R}^{2}$ & $\beta$ & 95\% C.I. & $\mathbf{R}^{2 \mathrm{~g}}$ \\
\hline Fast food (10 outlets/km²) & 200 m circular $^{\mathrm{d}}$ & $-0.20 * * *$ & $-0.30,-0.09$ & 0.15 & 0.11 & $-0.59,0.81$ & 0.21 \\
\hline & 400 m circular & $-0.27 * *$ & $-0.47,-0.07$ & 0.14 & 0.44 & $-0.16,1.04$ & 0.27 \\
\hline & 200 m network $^{\mathrm{e}}$ & $-0.13^{* *}$ & $-0.20,-0.05$ & 0.14 & -0.07 & $-0.48,0.34$ & 0.19 \\
\hline & 400 m network & $-0.23^{* * *}$ & $-0.35,-0.10$ & 0.15 & 0.14 & $-0.51,0.80$ & 0.24 \\
\hline & $200 \mathrm{~m} \mathrm{GPS}^{\mathrm{f}}$ & $-0.36^{*}$ & $-0.70,-0.02$ & 0.13 & -0.98 & $-2.79,0.83$ & 0.16 \\
\hline & $400 \mathrm{~m}$ GPS & -0.35 & $-0.70,0.00$ & 0.12 & -0.19 & $-2.14,1.77$ & 0.14 \\
\hline Wait service (10 outlets/km²) & $200 \mathrm{~m}$ circular & $-0.17 * * *$ & $-0.25,-0.08$ & 0.15 & 0.30 & $-0.43,1.03$ & 0.21 \\
\hline & 400 m circular & 0.30 & $-0.43,1.03$ & 0.15 & -0.37 & $-1.09,0.35$ & 0.27 \\
\hline & 200 m network & -0.38 & $-1.09,0.34$ & 0.13 & -0.11 & $-0.25,0.48$ & 0.19 \\
\hline & 400 m network & $-0.14^{* * *}$ & $-0.22,-0.07$ & 0.15 & 0.18 & $-0.25,0.62$ & 0.24 \\
\hline & 200 m GPS & $-0.30^{*}$ & $-0.60,-0.00$ & 0.12 & 0.86 & $-1.22,2.94$ & 0.16 \\
\hline & $400 \mathrm{~m}$ GPS & -0.35 & $-0.71,0.00$ & 0.12 & 0.03 & $-2.43,2.48$ & 0.14 \\
\hline Corner store (10 outlets/km²) & $200 \mathrm{~m}$ circular & -0.85 & $-2.02,0.32$ & 0.12 & 0.20 & $-1.36,1.75$ & 0.21 \\
\hline & $400 \mathrm{~m}$ circular & -0.78 & $-2.54,0.97$ & 0.11 & 0.49 & $-2.30,3.28$ & 0.27 \\
\hline & 200 m network & -0.04 & $-0.66,0.58$ & 0.10 & -0.08 & $-0.69,0.53$ & 0.19 \\
\hline & 400 m network & -0.56 & $-0.69,0.53$ & 0.11 & 0.20 & $-1.63,2.02$ & 0.24 \\
\hline & $200 \mathrm{~m}$ GPS & -1.53 & $-3.60,0.53$ & 0.11 & 0.13 & $-4.19,4.46$ & 0.16 \\
\hline & $400 \mathrm{~m}$ GPS & -1.15 & $-3.74,1.45$ & 0.11 & -0.86 & $-6.90,5.18$ & 0.14 \\
\hline Grocery store (1 outlet/km²) & 200 m circular & $-0.14^{* * *}$ & $-0.20,-0.09$ & 0.18 & $-0.42^{*}$ & $-0.78,-0.07$ & 0.21 \\
\hline & $400 \mathrm{~m}$ circular & $-0.36 * * *$ & $-0.52,-0.20$ & 0.19 & $-1.02 * *$ & $-1.61,-0.43$ & 0.27 \\
\hline & 200 m network & $-0.15^{* * *}$ & $-0.23,-0.07$ & 0.16 & $-0.24^{*}$ & $-0.45,-0.02$ & 0.19 \\
\hline & 400 m network & $-0.186^{* * *}$ & $-0.27,-0.10$ & 0.18 & $-0.58 * * *$ & $-0.88,-0.29$ & 0.24 \\
\hline & $200 \mathrm{~m}$ GPS & $-0.68 *$ & $-1.28,-0.08$ & 0.13 & -0.54 & $-1.96,0.89$ & 0.16 \\
\hline & $400 \mathrm{~m}$ GPS & -0.82 & $-1.70,0.06$ & 0.13 & -0.15 & $-2.41,2.12$ & 0.14 \\
\hline Supermarket (1 outlet/km²) & $200 \mathrm{~m}$ circular & -0.06 & $-0.66,0.54$ & 0.10 & 0.24 & $-0.51,0.99$ & 0.21 \\
\hline & 400 m circular & -0.30 & $-0.83,0.22$ & 0.12 & $1.67^{* *}$ & $0.52,2.83$ & 0.27 \\
\hline & 200 m network & -0.03 & $-0.26,0.21$ & 0.10 & -0.11 & $-0.39,0.16$ & 0.19 \\
\hline & 400 m network & -0.10 & $-0.93,0.74$ & 0.10 & 0.64 & $-0.23,1.52$ & 0.24 \\
\hline & $200 \mathrm{~m}$ GPS & -1.14 & $-2.33,0.06$ & 0.12 & 0.38 & $-2.07,2.82$ & 0.16 \\
\hline & $400 \mathrm{~m}$ GPS & $-1.57^{*}$ & $-3.01,-0.13$ & 0.13 & -1.27 & $-6.05,3.51$ & 0.14 \\
\hline
\end{tabular}
population density, and other food environment variables; ${ }^{\circ}$ C.I.: Confidence Interval; ${ }^{\mathrm{d}}$ Residential circular buffer; ${ }^{~}$ Residential network buffer; ${ }^{\mathrm{I}} \mathrm{GPS}$-defined activity space buffer; ${ }^{\mathrm{B}} \mathrm{Model} 2 \mathrm{R}^{2}$ values are presented the same for each food outlet, as all five food outlets variables are adjusted. 
2011; Christian, 2012). A final limitation of this work is that our study did not assess where participants were effectively purchasing foods.

\section{Conclusions}

We examined associations between the densities of food outlet types within residential and GPS activity spaces and both BMI and BP among low-income public housing residents in NYC. Results from the study overall show that grocery stores in residential neighbourhoods are associated with lower BMI and BP. Supermarkets in residential neighbourhoods, on the other hand, were associated with higher BP. Future research using longitudinal designs should examine how neighbourhood food environments around residences and GPS activity spaces are associated with cardiovascular disease risk among low-income residents.

\section{References}

Aktas Arnas Y, 2006. The effects of television food advertisement on children's food purchasing requests. Pediatr Int 48:138-45.

Almanza E, Jerrett M, Dunton G, Seto E, Pentz MA, 2012. A study of community design, greenness, and physical activity in children using satellite, GPS and accelerometer data. Health \& Place 18:46-54.

Boruff BJ, Nathan A, Nijënstein S, 2012. Using GPS technology to (re)-examine operational definitions of 'neighbourhood' in place-based health research. Int J Health Geogr 11:22.

Cetateanu A, Jones A, 2016. How can GPS technology help us better understand exposure to the food environment? A systematic review. SSM Popul Health 2:196-205.

Chaix B, 2009. Geographic life environments and coronary heart disease: a literature review, theoretical contributions, methodological updates, and a research agenda. Annu Rev Public Health 30:81-105.

Chaix B, Kestens Y, Perchoux C, Karusisi N, Merlo J, Labadi K, 2013a. An interactive mapping tool to assess individual mobility patterns in neighborhood studies. Am J Prev Med 43:440-50.

Chaix B, Meline J, Duncan S, Merrien C, Karusisi N, Perchoux C, Lewin A, Labadi K, Kestens Y, 2013b. GPS tracking in neighborhood and health studies: a step forward for environmental exposure assessment, a step backward for causal inference?. Health Place 21:46-51.

Christian WJ, 2012. Using geospatial technologies to explore activity-based retail food environments. Spat Spatiotemporal Epidemiol 3:287-95.

Diez Roux AV, 2003. Residential environments and cardiovascular risk. J Urban Health 80:569-89.

Dubowitz T, Ghosh-Dastidar M, Eibner C, Slaughter ME, Fernandes M, Whitsel EA, Bird CE, Jewell A, Margolis KL, Li W, Michael YL, Shih RA, Manson JE, Escarce JJ, 2012. The Women's Health Initiative: The food environment, neighborhood socioeconomic status, BMI, and blood pressure. Obesity (Silver Spring) 20:862-71.

Duncan DT, Kapadia F, Regan SD, Goedel WC, Levy MD, Barton SC, Friedman SR, Halkitis PN, 2016a. Feasibility and acceptability of Global Positioning System (GPS) methods to study the spatial contexts of substance use and sexual risk behaviors among young men who have sex with men in New York City: A P18 Cohort Sub-Study. Plos One 11:e0147520.

Duncan DT, Kawachi I, 2018. Neighborhoods and Health. 2nd ed. Oxford, UK: Oxford University Press.

Duncan DT, Regan SD, 2015. Mapping multi-day GPS data: a cartographic study in NYC. J Maps 1-3.

Duncan DT, Regan SD, Shelley D, Day K, Ruff RR, Al-Bayan M, Elbel B, 2014. Application of global positioning system methods for the study of obesity and hypertension risk among low-income housing residents in New York City: a spatial feasibility study. Geospat Health 9:57-70.

Duncan DT, Ruff RR, Chaix B, Regan SD, Williams JH, Ravenell J, Bragg MA, Ogedegbe G, Elbel B, 2016b. Perceived spatial stigma, body mass index and blood pressure: a global positioning system study among low-income housing residents in New York City. Geospat Health 11:164-73.

Duncan DT, Tamura K, Regan SD, Athens J, Elbel B, Meline J, AlAjlouni YA, Chaix B, 2017. Quantifying spatial misclassification in exposure to noise complaints among lowincome housing residents across New York City neighborhoods: a Global Positioning System (GPS) study. Ann Epidemiol 27:67-75.

Fiechtner L, Block J, Duncan DT, Gillman MW, Gortmaker SL, Melly SJ, Rifas-Shiman SL, Taveras EM, 2013. Proximity to supermarkets associated with higher body mass index among overweight and obese preschool-age children. Prev Med 56:218-21.

Ford PB, Dzewaltowski DA, 2010. Limited supermarket availability is not associated with obesity risk among participants in the Kansas WIC Program. Obesity (Silver Spring) 18:1944-51.

Gustafson AA, Lewis S, Wilson C, Jilcott-Pitts S, 2012. Validation of food store environment secondary data source and the role of neighborhood deprivation in Appalachia, Kentucky. BMC Public Health 12:688.

Hattori A, An R, Sturm R, 2013. Neighborhood food outlets, diet, and obesity among California adults, 2007 and 2009. Prev Chronic Dis 10:E35.

Hess PL, Reingold JS, Jones J, Fellman MA, Knowles P, Ravenell JE, Kim S, Raju J, Ruger E, Clark S, Okoro C, Ogunji O, Knowles P, Leonard D, Wilson RP, Haley RW, Ferdinand KC, Freeman A, Victor RG, 2007. Barbershops as hypertension detection, referral, and follow-up centers for black men. Hypertension 49:1040-6.

Kaiser P, Diez Roux AV, Mujahid M, Carnethon M, Bertoni A, Adar SD, Shea S, McClelland R, Lisabeth L, 2016. Neighborhood environments and incident hypertension in the multi-ethnic study of atherosclerosis. Am J Epidemiol 183:988-97.

Kurukulasuriya LR, Stas S, Lastra G, Manrique C, Sowers JR, 2011. Hypertension in obesity. Med Clin North Am 95:903-17.

Leal C, Chaix B, 2011. The influence of geographic life environments on cardiometabolic risk factors: a systematic review, a methodological assessment and a research agenda. Obes Rev 12:217-30.

Li F, Harmer P, Cardinal BJ, Vongjaturapat N, 2009. Built environment and changes in blood pressure in middle aged and older adults. Prev Med 48:237-41.

Matthews SA, 2011. Spatial polygamy and the heterogeneity of place: studying people and place via egocentric methods. In: 
Burton LM, Kemp SP, Leung M, Matthews SA, Takeuchi DT, eds. Communities, Neighborhoods, and Health. New York, NY: Springer.

Merai R, Siegel C, Rakotz M, Basch P, Wright J, Wong B, Thorpe P, 2016. CDC Grand Rounds: a public health approach to detect and control hypertension. MMWR Morb Mortal Wkly Rep 65:1261-4.

Morland K, Diez Roux AV, Wing S, 2006. Supermarkets, other food stores, and obesity: the atherosclerosis risk in communities study. Am J Prev Med 30:333-9.

Mujahid MS, Diez Roux AV, Morenoff JD, Raghunathan TE, Cooper RS, Ni H, Shea S, 2008. Neighborhood characteristics and hypertension. Epidemiology 19:590-8.

Narkiewicz K, 2006. Diagnosis and management of hypertension in obesity. Obes Rev 7:155-62.

Oliver LN, Schuurman N, Hall AW, 2007. Comparing circular and network buffers to examine the influence of land use on walking for leisure and errands. Int J Health Geogr 6:41.

Perchoux C, Chaix B, Cummins S, Kestens Y, 2013. Conceptualization and measurement of environmental exposure in epidemiology: accounting for activity space related to daily mobility. Health Place 21:86-93.

Ravenell J, Thompson H, Cole H, Plumhoff J, Cobb G, Afolabi L, Boutin-Foster C, Wells M, Scott M, Ogedegbe G, 2013. A novel community-based study to address disparities in hypertension and colorectal cancer: a study protocol for a randomized control trial. Trials 14:287.

Rodríguez DA, Cho GH, Evenson KR, Conway TL, Cohen D, Ghosh-Dastidar B, Pickrel JL, Veblen-Mortenson S, Lytle LA,
2012. Out and about: association of the built environment with physical activity behaviors of adolescent females. Health \& Place 18:55-62.

Shearer C, Rainham D, Blanchard C, Dummer T, Lyons R, Kirk S, 2015. Measuring food availability and accessibility among adolescents: Moving beyond the neighbourhood boundary. Soc Sci Med 133:322-30.

Stark JH, Neckerman K, Lovasi GS, Konty K, Quinn J, Arno P, Viola D, Harris TG, Weiss CC, Bader MDM, 2013. Neighbourhood food environments and body mass index among New York City adults. J Epidemiol Commun Health 67:736-42.

Tamura K, Elbel B, Chaix B, Regan SD, Al-Ajlouni YA, Athens JK, Meline J, Duncan DT, 2017. Residential and GPS-defined activity space neighborhood noise complaints, body mass index and blood pressure among low-income housing residents in New York City. J Commun Health 42:974-82.

Thornton LE, Crawford DA, Lamb KE, Ball K, 2017. Where do people purchase food? A novel approach to investigating food purchasing locations. Int J Health Geogr 16:9.

Zenk SN, Schulz AJ, Matthews SA, Odoms-Young A, Wilbur J, Wegrzyn L, Gibbs K, Braunschweig C, Stokes C, 2011. Activity space environment and dietary and physical activity behaviors: a pilot study. Health Place 17:1150-61.

Zick CD, Smith KR, Fan JX, Brown BB, Yamada I, KowaleskiJones L, 2009. Running to the store? The relationship between neighborhood environments and the risk of obesity. Soc Sci Med 69:1493-500. 